\title{
Características das experiências de parto e pós-parto de estudantes de Psicologia
}

\author{
Características de las experiencias de parto y posparto de estudiantes de \\ Psicología
}

\section{Characteristics of childbirth and post childbirth experiences of Psychology students}

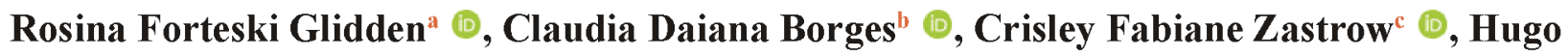 Guelere Rodrigues $^{d}{ }^{-}$, Paula Cristiane Bernstein ${ }^{e}(-)$ e Raquel Rosa Grigolo ${ }^{f}$}

${ }^{a}$ Centro Universitário Leonardo da Vinci, Guaramirim/SC, e Universidade Federal do Paraná, Curitiba/PR, Brasil. Psicóloga. Mestra e Doutoranda em Educação pela UFPR. Professora da Univinci/Uniasselvi. Endereço institucional: Rodovia BR 280, 15885 - Imigrantes, Guaramirim- SC, Brasil.89.270-000. E-mail: rsforteski@gmail.com.

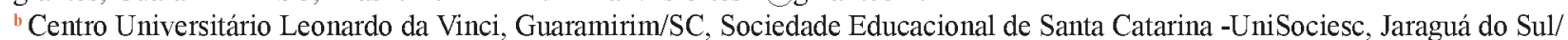
SC, e Universidade Federal de Santa Catarina, Florianópolis/SC, Brasil. Psicóloga. Mestra e Doutoranda em Psicologia pela UFSC. Professora da Univinci/Uniasselvi e da UniSociesc. E-mail: claudia.daiana@gmail.com.

${ }^{c}$ Psicóloga pela Univinci - Centro Universitário Leonardo da Vinci/Uniasselvi, Guaramirim/SC, Brasil. E-mail: crisleyzastrow@gmail.com.

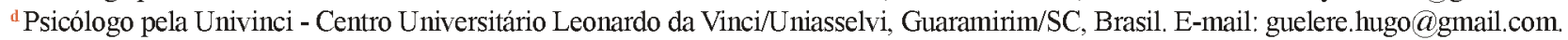

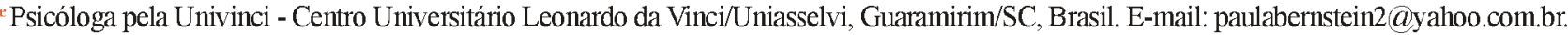
${ }^{\text {f}}$ Psicóloga pela Univinci - Centro Univeritário Leonardo da Vinci/Uniasselvi, Graramirim/SC, Brasil. E-mail: raquelgrigolo@hotmail.com.

Resumo: O período da gestação e o momento do parto suscitam sentimentos diversos, a depender das características da vivência de cada mulher, podendo ser um fator facilitador ou dificultador da maternidade. Esta pesquisa buscou investigar as características gerais das experiências de parto e pós-parto de acadêmicas de Psicologia. Trata-se de um estudo quantitativo. Foi aplicado um questionário em 28 acadêmicas de uma instituição de ensino superior. Na análise foram geradas medidas descritivas. Os resultados mostraram que 46,4\% tiveram parto normal (PN), 42,9\%, parto cesárea (PC) e 10,7\% tiveram os dois. Das que realizaram PN, $68,8 \%$ passaram por indução, $93,8 \%$, por episiotomia e $75,0 \%$ amamentaram na primeira hora de vida da criança. Dentre as que fizeram PC, houve uma taxa menor de amamentação (46,7\%) nesse período. Sugere-se que levantar questões relacionadas à experiência de parto pode permitir a elaboração de estratégias efetivas de empoderamento para gestantes na tomada de decisão sobre seu parto.

Palavras-chave: Parto normal; Cesárea; Parturiente; Período pós-parto

Como citar o artigo: GLIDDEN, R. F.; BORGES, C. D.; ZASTROW, C. F.; RODRIGUES, H. G.; BERNSTEIN, P. C.; GRIGOLO, R. R. Características das experiências de parto e pós-parto de estudantes de Psicologia. Revista de Ciências Humanas, Florianópolis, v. 53, 2019 DOI: 10.5007/2178-4582.2019.e57140 você pode compartilhar, adaptar, para qualquer fim, desde que atribua a autoria da obra, forneça um link para a licença, e indicar se foram feitas alterações. 
Resumen: El período de embarazo y el momento del parto dan lugar a diferentes sentimientos, dependiendo de las características de la experiencia de cada mujer, que pueden ser un facilitador o un obstáculo para la maternidad. Esta investigación buscó investigar las características generales de las experiencias de parto y posparto de estudiantes de psicología. Es un estudio cuantitativo. Se aplicó un cuestionario a 28 estudiantes de una institución de educación superior. En el análisis, se generaron medidas descriptivas. Los resultados mostraron que el $46.4 \%$ tuvo parto normal (PN), el $42.9 \%$ un parto por cesárea (PC) y el 10.7\% tuvo ambos. De aquellas que se sometieron a PN, 68.8\% se sometieron a inducción, $93.8 \%$ se sometieron a la episiotomía y $75.0 \%$ amamantaron en la primera hora de vida del niño o de la niña. Entre las que tenían $\mathrm{PC}$, hubo una tasa más baja de lactancia materna $(46,7 \%)$ en este período. Se sugiere que plantear preguntas relacionadas con la experiencia del parto puede permitir la elaboración de estrategias efectivas de empoderamiento para las mujeres embarazadas en la toma de decisiones sobre su parto.

Palabras clave: Parto normal; Cesárea; Parturient; Período posparto.

\begin{abstract}
The period of pregnancy and the moment of delivery give rise to different feelings, depending on the characteristics of each woman's experience, which can be a facilitator or a hindrance of motherhood. This research sought to investigate the general characteristics of childbirth/delivery and postpartum experiences of Psychology students. This is a quantitative study. A questionnaire was applied to 28 students from a higher education institution. In the analysis, descriptive measures were generated. The results showed that $46.4 \%$ had a normal delivery, $42.9 \%$ had a caesarean delivery, and $10.7 \%$ had both. From those who had normal delivery, $68.8 \%$ underwent induction, $93.8 \%$ had an episiotomy and $75 \%$ breastfed in the child's first hour of life. Among those who had cesarean delivery, there was a lower rate of breastfeeding $(46.7 \%)$ in this period. It is suggested that raising questions related to the experience of childbirth may allow the development of effective empowerment strategies for pregnant women in making decisions about their childbirth.
\end{abstract}

Key-words: Normal birth; Cesarean delivery; Parturient; Postpartum period.

\title{
1 INTRODUÇÃO
}

No decorrer da história a condução do parto foi deixando de ser natural, mediada pela cultura, passando a ser institucionalizada. Até o século XVII o parto era compreendido como uma relação afetiva entre a parturiente e os familiares. O nascimento era espontâneo e involuntário, no final da gestação. Porém, os índices de mortalidade eram altos. A institucionalização do parto inicia-se com a intervenção do médico para redução das taxas de mortalidade. A cesariana passa a ser uma alternativa para casos de risco de óbito, deixando o médico em posição de controle no parto. Com os avanços científicos surgem a medicalização e a separação dos familiares no auxílio ao parto. Neste cenário, as parturientes ficam aos cuidados de terceiros (MALDONADO, 2013).

Assim, de um lado a institucionalização do parto e o controle científico advindo deste processo auxiliaram na redução da mortalidade infantil, de outro, estas mudanças paulatinamente reduziram também o protagonismo da mulher e a atenção à fisiologia e ao tempo próprio de cada gestação. A preocupação atual repousa em diminuir o número de partos cesáreos desnecessários. Para tanto, os procedimentos hospitalares precisam constituir-se de ações humanizadoras, favorecendo experiências mais positivas das mulheres com o parto normal.

Para além da redução de cesáreas, a humanização do parto tem como pressuposto o direito da mulher de ser protagonista e receber auxílio de forma humanizada, envolve o pré e pós-parto, entendendo esse processo como um momento importante, cercado por inseguranças e emoções, exigindo do profissional uma assistência que possibilite a atenção integral à mulher (NASCIMENTO; SILVA; VIANA, 2018). A humanização inclui o direito à escolha da parturiente a um parto respeitoso, independente da via, e possibilita a ruptura com práticas instituídas e danosas ao processo do parto (BARROS et al., 2018).

A humanização do parto visa romper com uma perspectiva fragmentada da assistência e que pouco considera a experiência da mulher. Para isso, é necessário fortalecer boas práticas de atenção ao parto e ao nascimento e resgatar o protagonismo da mulher. É preciso ampliar o cuidado e oferecê-lo 
de forma singular e integral, rompendo com perspectivas de fragmentação do processo e contando com comprometimento dos profissionais da saúde no intuito de potencializar a articulação dos serviços de saúde pela efetivação do cuidado humanizado (PEREIRA et al., 2018). Para que esta efetivação ocorra, são necessárias a articulação dos serviços de saúde, estrutura física adequada e capacitação dos profissionais (NASCIMENTO; SILVA; VIANA, 2018).

O estabelecimento de uma relação de confiança entre a parturiente e os profissionais da saúde representa uma importante estratégia no processo de cuidado, para isto, é essencial que a subjetividade e as necessidades de cada mulher sejam consideradas, bem como suas escolhas sejam validadas (OLIVEIRA; PENNA, 2018). Embora muitos esforços tenham sido empreendidos para a implantação e fortalecimento da humanização do parto e nascimento, ainda se fazem necessários muitos avanços no intuito de fortalecer a atenção humanizada no pré-parto, parto e puerpério, seja o parto cesáreo ou normal (BARROS et al., 2018; PEREIRA et al., 2018).

Em uma gestação saudável, o parto normal atende de maneira mais satisfatória às necessidades da mulher e do bebê. Esta via de parto tem menor probabilidade de gerar complicações e favorece o protagonismo da mulher (FERREIRA JUNIOR et al. 2017). Cabe pontuar ainda que, conforme esclarecem Andrade e Aggio (2014, p.2), o parto difere de outros eventos que demandam cuidados hospitalares, pois "o processo de parturição é fisiológico, normal, necessitando, na maioria das vezes, apenas de apoio, acolhimento, atenção, e o mais importante, humanização".

Das mulheres que fazem parto cesáreo emergem geralmente relatos de insatisfação quanto à dor do período pós-operatório (FERREIRA JUNIOR et al. 2017). Apesar de o parto normal ser efetivamente mais benéfico para a mãe e para o bebê, é preciso ressaltar, porém, que em alguns casos a indicação para realização da cesariana é necessária. Exemplos destes casos são: situações em que o feto não é reativo, tem apresentação pélvica, quando a gestante tem HIV, quando a posição é transversa, entre outras situações específicas sobre as quais o obstetra deve avaliar a necessidade da realização da cesárea (BRASIL, 2014).

O parto cesáreo é considerado uma cirurgia de grande porte que, quando indicada adequadamente, pode salvar vidas. Porém, estudos têm apontado que a opção da mulher por esta via nem sempre está atrelada à ocorrência de complicações na gestação. A literatura (BRASIL, 2014; FERREIRA JUNIOR, 2017; MEDEIROS et al., 2017) identifica como um dos principais benefícios desta via o menor nível de dor durante o parto, em função do uso de anestesia. Este benefício aparece como a motivação mais frequente no relato de mulheres brasileiras que optam pela cesárea como via de parto (CÂMARA et al., 2016).

Ainda assim, há uma predileção, pelo menos inicialmente, das mulheres pelo parto normal (WEIDLE et al., 2014; SANTOS; MELO; LEAL, 2015). As gestantes que participaram da pesquisa de Figueiredo et al. (2010) exemplificaram essa preferência. As razões para esta escolha, apontadas pelas participantes deste estudo, foram a expectativa de um parto sem intercorrências e de recuperação rápida. De fato, o parto normal possibilita algumas vantagens para a díade mãe-bebê, como menores índices de prematuridade, amadurecimento do sistema respiratório do bebê, menor dor pós-parto, infecção puerperal menos frequente, facilitação do aleitamento materno, recuperação mais rápida, menores custos, menores cicatrizes e baixos riscos de morte. Como desvantagem no parto normal pode-se destacar a dor no trabalho de parto (BRASIL, 2014).

Em relação à escolha da via de parto pela gestante, alguns fatores têm sido apontados com frequência pela literatura como influentes neste processo. Medeiros et al. (2017) citam: características das experiências de partos anteriores, opinião de familiares, pouco acesso à informação, características do cuidado ofertado no pré-natal e medo de questões relacionadas ao trabalho de parto. Figueiredo et al. (2010) reforçam que a influência do medo da dor e o relato da experiência de outras mulheres são relevantes na escolha. A falta de conhecimento é citada como fator influente no comportamento das gestantes por promover insegurança e deixá-las, por isso, mais vulneráveis a aceitar que a decisão seja tomada por outros (PATAH; MALIK, 2011; VELHO; SANTOS; COLLAÇO, 2014; WEIDLE et 
al., 2014). Preocupações relacionadas à estética, à manutenção da produtividade e à preservação da atividade sexual também são aspectos relevantes neste processo decisório (RISCADO; JANNOTTI; BARBOSA, 2016).

É preciso, dentro da gama de fatores de influência, dar ênfase à rede de relacionamentos da mulher, especialmente no que concerne a outras mulheres. O intercâmbio de informações entre familiares e amigas sobre as particularidades de suas experiências, boas ou ruins, pode levar a parturiente a realizar uma escolha que desconsidere as características do seu caso (SILVA; PRATES; CAMPELO, 2014). Na pesquisa de Lagomarsino et al. (2013), as participantes afirmaram que sua escolha sofreu influência direta das vivências e significados de outras mulheres conhecidas sobre as vias de parto. A parturiente bem informada é menos vulnerável à influência da opinião de outras pessoas, porque entende que a contextualização de cada gestação é fundamental nessa apreensão de significados.

A falta de humanização também tem papel decisivo na escolha da mulher. Histórias sobre dor, sofrimento e abusos no parto guiam a opinião das gestantes. Weidle et al. (2014) identificaram em seu estudo que conhecer a história de exposição de outras mulheres à violência obstétrica influencia negativamente a gestante, desestimulando-a a querer um parto normal. Deste modo, o parto normal é fortemente estigmatizado e o cesáreo emerge como a alternativa segura e que, adicionalmente, garante maior conforto. Resultados do estudo de Medeiros et al. (2017) ilustram esse processo de estigmatização que favorece o aumento do número de cesáreas. Nessa pesquisa a escolha do parto cesáreo foi justificada pelas participantes como a opção mais segura para evitar para o inesperado e um final trágico. Este posicionamento sugere um desconhecimento das parturientes sobre os riscos e benefícios de cada via de parto.

O parto é um momento único na vida da gestante, e a equipe hospitalar deve procurar desenvolver suas estratégias de cuidado com vistas à humanização desse processo. Entende-se por violência obstétrica uma ampla gama de ações que compreendem, por exemplo, desde a omissão à parturiente de informações sobre os procedimentos de intervenção realizados, até a humilhação verbal durante a parturição. Pela intensidade emocional que caracteriza as fases do parto, estas ações são pouco reconhecidas pelas mulheres como violência. Por isso, faz-se necessário o seu empoderamento, desde as consultas pré-natais, de modo a instrumentalizar a gestante para que ela decida de forma consciente sobre seu corpo e seu bebê, e também a capacitando a identificar e denunciar a violência obstétrica (ANDRADE; AGGIO, 2014).

Assim, entende-se que o período da gestação e o momento do parto suscitam sentimentos diversos, a depender das características da vivência de cada mulher, podendo ser um fator contribuinte ou dificultador da maternidade e de novas gestações. Frente a estas preocupações, foi objetivo deste artigo investigar as características gerais das experiências de parto e pós-parto de acadêmicas de Psicologia.

\section{MÉTODO}

Trata-se de uma pesquisa quantitativa, descritiva e exploratória, para a qual foi utilizada uma amostra de conveniência. A pesquisa foi submetida e aprovada por um Comitê de Ética (Parecer $\mathrm{n}^{\circ}$ 1.942.472), tendo sido utilizado o Termo de Consentimento Livre e Esclarecido (TCLE). Como instrumento de coleta de dados empregou-se um questionário semiestruturado, construído a partir da literatura da área. Este instrumento era composto de 48 questões, sendo 13 referentes a características sociodemográficas das participantes, cinco questões fechadas em escala Likert que abordavam o conhecimento das participantes sobre aspectos específicos das vias de parto e 30 questões fechadas que investigavam as características da experiência de parto e pós-parto das participantes, os fatores de influência na sua escolha e seus níveis de satisfação com o atendimento da equipe de saúde, com a recuperação no período pós-parto e com a experiência de modo geral com o tipo de parto experienciado. 
A aplicação foi feita coletivamente nas salas de aula das turmas de Psicologia em diferentes dias previamente agendados com o professor de cada turma, dentro de um período de duas semanas, na faculdade campo da pesquisa. Os pesquisadores explicavam a pesquisa, seus objetivos e procedimentos, a partir da apresentação do TCLE, em frente à turma. Após, os questionários e termos eram distribuídos para aquelas estudantes que aceitaram participar. Elas preencheram os questionários em suas carteiras, individualmente. O tempo médio de aplicação foi de 25 minutos.

\section{ANÁLISE E DISCUSSÃO DOS RESULTADOS}

A análise foi feita por medidas descritivas, como porcentagens, médias, desvio padrão e frequências. A discussão se deu a partir da literatura da área, com foco em publicações que abordam criticamente aspectos relevantes para a humanização do processo de parto, incluindo os períodos pré-parto e pós-parto, tendo como base ainda as orientações de órgãos referência para questões pertinentes à gestação e à parturição, em contexto nacional e global, como o Ministério da Saúde e a Organização Mundial da Saúde.

\subsection{PARTICIPANTES}

Participaram da pesquisa 28 mulheres que já haviam passado pela experiência de parto do curso de Psicologia de uma faculdade privada do norte de Santa Catarina. Essa amostra representa a totalidade das acadêmicas mães matriculadas no curso de Psicologia da instituição presentes no momento da aplicação, excetuando-se as que não tinham 18 anos completos. Não houve recusa de nenhuma estudante em participar da pesquisa.

Dentre estas, $37,0 \%(n=10)$ tinham idade entre 36 e 45 anos, $25,9 \%(n=7)$ tinham até 25 anos, $25,9 \%(n=7)$ entre 26 e 35 anos e $11,1 \%(n=3)$ mais de 46 anos. A média de idade constatada foi de 35,2 anos $(d p=1,00 \%)$. Quanto ao estado civil, a maior parte $(53,6 \%, \mathrm{n}=15)$ era casada. Em relação à religião, a maioria declarou-se católica $(53,6 \%, n=15)$ e a raça branca foi predominante $(78,6 \%$, $\mathrm{n}=22)$. Ainda, $67,9 \%(\mathrm{n}=19)$ estavam empregadas e $64,3 \%(\mathrm{n}=18)$ não possuíam graduação anterior completa. Por fim, em relação à quantidade de filhos, a maioria $(n=13)$ tinha apenas um, seguida das que tinham dois filhos $(\mathrm{n}=8)$ e três filhos $(\mathrm{n}=1)$. Porém, seis participantes não responderam esta questão.

\subsection{CARACTERÍSTICAS DOS PARTOS}

Em relação ao tipo de parto experienciado, as diferenças encontradas foram sutis, pois $13(46,4 \%)$ participantes tiveram apenas parto normal, $12(42,9 \%)$ tiveram apenas parto cesáreo e três $(10,7 \%)$ tiveram os dois tipos de parto. Essa proporção vai de encontro à literatura que, no geral, aponta níveis exponencialmente maiores de cesáreas (BRASIL, 2001; BRASIL, 2014; EUFRÁSIO, 2017). Também foi perguntado às participantes a respeito do tipo de parto realizado pela maioria das mulheres que elas conheciam, e a maior parte $(75,0 \%, \mathrm{n}=21)$ conhecia mais mulheres que tiveram parto cesárea, esta proporção parece se aproximar mais da relação apontada nos trabalhos supracitados. Este é um dado relevante porque sabe-se que a experiência de outra mulher pode influenciar de maneira decisiva na escolha do tipo de parto pela parturiente (LAGOMARSINO et al. 2013; MEDEIROS et al. 2017; SILVA; PRATES; CAMPELO, 2014; WEIDLE et al. 2014).

Porém, ainda que a quantidade de partos por tipo tenha se mantido marginalmente similar nesta pesquisa, considerando-se a proporção sugerida como adequada pela Organização Mundial da Saúde, os números excedem tal recomendação. Segundo este órgão, a opção por partos cesáreos não deveria ultrapassar 15\% do total de partos (OMS, 2014). Dados da Pesquisa Nacional de Demografia e Saúde 
da Criança e da Mulher (PNDS) de 2006 mostraram que a porcentagem de partos cesarianos chegou a 43,8\% no país, sendo ainda mais frequente nas Regiões Sudeste (51,7\%) e Sul (51,6\%) (BRASIL, 2009).

No Brasil, a alta prevalência de partos cesáreos se dá pela existência de uma 'cultura cesariana' (BRASIL, 2014). O parto cesáreo é uma intervenção médica realizada apenas em casos em que sua indicação pode salvar a vida da mãe e/ou do bebê, pois ela pode causar complicações significativas que vão desde sérias sequelas, até a morte, especialmente quando realizada em locais com pouca infraestrutura para este tipo de cirurgia (OMS, 2014).

Perguntou-se às participantes se elas mudaram de preferência sobre a via de parto no decorrer da gravidez, como foi essa mudança e se a sua preferência foi respeitada. Em resposta, $65,4 \%$ ( $n=17)$ relataram não terem mudado de ideia quanto ao tipo de parto no decorrer da gestação. Das que mudaram, $54,5 \%(n=6)$ queriam inicialmente o parto cesáreo e mudaram para parto normal, e 45,5\% $(n=5)$ queriam parto normal, mas mudaram para parto cesáreo. Contudo, 78,6\% $(n=22)$ das mulheres consideraram que a sua decisão pelo tipo de parto de sua preferência foi respeitada.

No período gestacional as mulheres recebem influência de muitas pessoas, o que torna latentes vários sentimentos e sensações que podem interferir na sua decisão (BRASIL, 2014; WEIDLE et al., 2014). A preferência inicial pelo tipo de parto é influenciada também pela forma com que a organização da assistência no pré-natal acontece. Por isso é preciso garantir que as recomendações dos protocolos assistenciais baseados em evidências científicas sejam práticas rotineiras nos sistemas público e privado (DOMINGUES et al., 2014).

As 28 mulheres participantes tiveram um total de 37 partos. Quanto à quantidade de partos por participante, $17(60,7 \%)$ tiveram apenas um, dez $(35,7 \%)$ tiveram dois e uma $(3,6 \%)$ teve três partos. Os dados obtidos pela pergunta sobre a quantidade de partos fornecem um resultado mais real do que os obtidos na pergunta sobre qual a quantidade de filhos biológicos das participantes, para conhecer quantos filhos biológicos as participantes tinham, pois nenhuma participante deixou de responder à questão sobre quantidade de partos. Dos 37 partos, 18 foram feitos no sistema público/SUS (Sistema Único de Saúde) e 19, no setor privado de saúde. Considerando somente os dados das participantes que só tiveram um tipo de parto $(\mathrm{n}=25)$, obtiveram-se os seguintes resultados: no setor público a maioria dos partos realizados foi normal $(n=10)$ e a minoria cesárea $(n=4)$. No setor privado, a maioria dos partos foi cesárea $(n=10)$, em contraposição a uma minoria que teve parto normal $(n=3)$. Estes dados concordam com a literatura. No Brasil, enquanto as taxas de cesárea diminuem no setor público (BRA$\mathrm{SIL}$, 2001), o setor privado permanece detentor do maior número de partos cesáreos, como mostram os estudos de Barbosa, Toé e Simões (2015) e Dias et al. (2008). A cesárea representa 84,6\% dos partos realizados no setor privado e 40,0\% no público (BRASIL, 2016).

O número médio de consultas realizadas durante o pré-natal das participantes foi de $9,52(d p=5,47)$, ficando acima do número mínimo atual recomendado pela Organização Mundial de Saúde (OMS, 2016), de oito consultas. É preciso ressaltar a importância da realização do pré-natal de maneira mais precoce possível na gestação. Pois "o período pré-natal requer cuidados especiais, tendo em vista o desenvolvimento adequado da gravidez, a obtenção de um parto sem complicações e o nascimento de uma criança sem problemas de saúde" (MARTINS, 2014, p. 1011). Nesta fase a gestante deve receber informações sobre a anatomia e a fisiologia materna, sobre as condutas que facilitam a sua participação ativa no nascimento, sexualidade, processo gestacional, mudanças corporais e emocionais esperadas, sobre o trabalho de parto, parto e puerpério, cuidados com o recém-nascido e informações sobre amamentação (BRASIL, 2001).

A maior parte dos partos normais $(n=6)$ aconteceu com 39 semanas, e dos cesáreos $(n=5)$ com 38 semanas. Houve recentemente mudanças na lei no que concerne ao momento em que a cesariana eletiva pode ser agendada. A Resolução ${ }^{\circ} 2.144$, de 17 de março de 2016, do Conselho Federal de Medicina, no artigo $2^{\circ}$, estabelece que, para garantir a segurança do feto, a cesariana a pedido da gestante, nas situações de risco habitual, somente poderá ser realizada a partir da $39^{a}$ semana de gestação, devendo haver registro em prontuário (CONSELHO FEDERAL DE MEDICINA, 2016). 
Esse posicionamento parte da noção de que o nascimento prematuro apresenta riscos significativos para o bebê, produzindo a demanda de alguns procedimentos pós-nascimento, como o uso de berço aquecido ou incubadora, para ajudá-lo a manter a temperatura corporal, de sonda gástrica para alimentar-se, de aparelhos com oxigênio para respirar adequadamente e medidas rigorosas de higiene para prevenir infecções (FONSECA; SCOCHI, 2009).

\subsection{SATISFAÇÃO COM O TIPO DE PARTO}

Caso engravidassem novamente, $83,3 \%(\mathrm{n}=10)$ das mulheres que tiveram apenas parto cesárea e $61,5 \%(n=8)$ das mulheres que tiveram apenas parto normal disseram que gostariam de ter o mesmo tipo de parto já experienciado. As diferenças se acentuaram mais quando estas participantes classificaram sua experiência em níveis de satisfação. A Tabela 1 apresenta esta avaliação em relação às suas experiências com parto normal e cesárea.

Tabela 1: Níveis de satisfação da gestante quanto à experiência por tipo de parto

\begin{tabular}{lcccc}
\hline Níveis & Normal & Normal & Cesárea & Cesárea \\
& $(\%)$ & $(f)$ & $(\%)$ & $(f)$ \\
\hline Ótima & $46,2 \%$ & 6 & $41,7 \%$ & 5 \\
Boa & $15,4 \%$ & 2 & $50,0 \%$ & 6 \\
Ruim & $7,7 \%$ & 1 & $8,3 \%$ & 1 \\
Péssima & $30,8 \%$ & 4 & $00,0 \%$ & 0 \\
\hline Total & $100 \%$ & 13 & $100 \%$ & 12 \\
\hline
\end{tabular}

$f:$ número de respostas, não de participantes.

Fonte: Própria pesquisa.

Os dados da Tabela 1 mostram que 91,7\% das mulheres com experiência apenas de parto cesáreo a classificaram de forma positiva e $61,6 \%$ das mulheres com experiência de parto normal a classificaram da mesma forma. Já $38,5 \%$ das mulheres que tiveram parto normal classificaram sua experiência negativamente e $8,3 \%$ das mulheres que tiveram parto cesáreo a classificaram da mesma forma. De modo geral, podem-se observar maiores níveis de satisfação positiva das mulheres que tiveram apenas a experiência de parto cesáreo.

Em estudo realizado em uma maternidade do Rio de Janeiro, 70,0\% das mulheres que foram entrevistadas classificaram sua experiência de parto como boa ou muito boa e $16,7 \%$ acharam-na ruim ou muito ruim. Nesse estudo os fatores que contribuíram para que a percepção do parto fosse negativa foram: o sofrimento no parto, a má atenção da equipe, complicações do bebê e o parto demorado e/ou difícil. De outro lado, as características que apontaram uma percepção mais positiva do parto foram: parto rápido, o bom tratamento da equipe, o pouco sofrimento e o bom estado da mãe e do bebê (DOMINGUES; SANTOS; LEAL, 2004). Outro estudo realizado por Teles et al. (2010), com 105 puérperas internadas em alojamento conjunto de maternidade escola no Estado do Ceará, apontou que o fator que mais influenciou na percepção positiva ou negativa do parto foi a presença de um acompanhante. As principais ações realizadas pelo acompanhante estiveram relacionadas a apoio emocional, ou seja, estar presente o tempo todo, dar força e observar todo o processo do parto. 


\subsection{CONHECIMENTO SOBRE PARTO}

As participantes foram investigadas sobre algumas questões referentes ao seu conhecimento sobre as vias de parto. Nesta direção, foi perguntado inicialmente se elas se consideravam bem informadas sobre os riscos e benefícios de cada tipo de parto, com $82,1 \%(n=23)$ se considerando bem informadas. Após, pediu-se que elas avaliassem o nível de seu conhecimento referente ao mesmo tema, em uma escala Likert; $82,1 \%(n=23)$ o avaliaram como bom, 14,3\% $(n=4)$ como ótimo e 3,6\% $(n=1)$ como ruim.

Em seguida foram apresentadas diferentes afirmações, a primeira foi "o parto normal gera mais benefícios para a mãe e o bebê". Diante desta afirmação, $42,3 \%(n=11)$ concordaram muito, 30,8\% $(n=8)$ concordaram, 19,2\% $(n=5)$ concordaram pouco e 7,7\% $(n=2)$ discordaram. Observa-se que, ainda que se note maiores níveis de concordância com a afirmação, houve um número considerável de mulheres $(\mathrm{n}=7)$ que concordaram pouco ou discordaram da associação apontada.

O parto normal tem o benefício de não provocar dores nos pós-parto e de favorecer a recuperação rápida da mulher, permitindo também a criação mais rápida de vínculo com o bebê, pois a interação entre os dois é instantânea. Neste tipo de parto o número de drogas transmitidas para o recém-nascido é menor, porque a mãe não recebe medicações na mesma proporção do que na cesárea. Ele também evita cicatrizes e que a mulher seja submetida a procedimentos desnecessários. Para o bebê este tipo de parto possibilita o amadurecimento do sistema imunológico, pois quando ele passa pelo canal vaginal o tórax é comprimido, ajudando na expulsão do líquido amniótico dos pulmões, e o aleitamento materno é geralmente antecipado (UNICEF, 2017).

Outra afirmação colocada para análise das participantes foi "o parto é um evento fisiológico, não médico". Com esta, $57,1 \%(\mathrm{n}=16)$ concordaram, $21,4 \%(\mathrm{n}=6)$ concordaram muito, $14,3 \%(\mathrm{n}=4)$ concordaram pouco e $7,1 \%(\mathrm{n}=2)$ discordaram. Observa-se também neste caso que, apesar de os níveis de concordância serem bons, houve participantes $(n=6)$ que concordaram pouco e que discordaram.

$O$ parto é um evento fisiológico que, na maior parte das vezes, pode correr de maneira natural e espontânea (ANDRADE; AGGIO, 2014; MONTESCHIO et al., 2016). No Brasil, porém, o modelo de assistência obstétrica e neonatal ainda é visto como problema médico e parte do pressuposto de que todas as gestações são patológicas, até que se prove o contrário (BRASIL, 2014). Com isso, o parto deixou de ser um acontecimento natural feminino, passando a ser um evento médico. Assim, mitificou-se o parto vaginal, fazendo com que esse tipo de parto se tornasse desconhecido e, portanto, amedrontador para as mulheres (WEIDLE et al., 2014).

O parto deve ser um momento de reafirmação da autonomia da mulher. Entretanto, o medo do parto vaginal a influencia negativamente e este sentimento a impossibilita de exercer sua capacidade de parir e de ter o entendimento de que o parto normal é melhor para mãe e bebê. A decisão da escolha sobre a via de parto está se tornando uma opção da mulher, e não uma indicação técnica. Contudo, esta opção, na maioria das vezes, é feita sem conhecimento e sem uma orientação adequada, passando a ser uma indução que vem a diminuir a sua autonomia (WEIDLE et al., 2014).

A parturiente deve ter participação ativa e ser protagonista no processo do parto (KOTTWITZ; GOUVEIA; GONÇALVES, 2018) e a rede de saúde deve atuar de forma integrada para possibilitar uma assistência de qualidade para a gestante (PEREIRA et al., 2018). O período gravídico-puerperal da mulher deve contar com uma assistência integral, com prioridade no serviço de Atenção Básica, pois ela precisa receber informações para atuar ativamente nas escolhas. A opção da via de parto deve atender às particularidades da gestação da mulher, e não às tendências culturais e sociais de uma época ou à conveniência técnica do profissional que a assiste (MELO, 2016).

\subsection{PARTOS NORMAIS}

Algumas questões foram direcionadas apenas às participantes $(\mathrm{n}=16)$ que passaram por parto normal, são estas: ocorrência de indução, uso de episiotomia, presença de doula, uso de analgesia e níveis de dor. 
Os dados encontrados mostram que, durante o processo de parto, $68,8 \%(\mathrm{n}=11)$ das participantes passaram por indução em situação de parto normal. Lemes et al. (2015) realizaram um levantamento da literatura com foco na percepção de puérperas em relação à indução do parto. Os resultados se mostraram polarizados, de um lado observou-se satisfação com a redução do tempo de trabalho de parto, pela aceleração da dilatação, de outro as participantes destacaram o incômodo com o aumento dos níveis de dor. As autoras concluíram que a maneira como as puérperas percebem a indução do parto "está diretamente relacionada com a quantidade e qualidade de informação e conhecimento que as gestantes possuem em relação aos seus direitos durante o trabalho de parto e quanto à finalidade da indução do mesmo" (p. 60).

Souza, Amorim e Neto (2010, p. 277) esclarecem que "a indução do parto consiste em estimular artificialmente as contrações uterinas coordenadas e efetivas antes de seu início espontâneo". Para os autores ela é indicada em diversas situações clínicas como: gestações prolongadas, pré-eclâmpsia, diabetes, redução da quantidade de líquido amniótico, rotura prematura de membranas e restrição do crescimento fetal. Haddad e Cecatti (2011) acrescentam que outras condições, como síndromes hipertensivas e colagenoses, também são indicação para indução do parto. Porém, é preciso adotar intervenções que tornem o parto vaginal mais seguro, evitando práticas prejudiciais, inoportunas e desnecessárias, que podem ser consideradas fator de risco para a mãe e bebê (HADDAD; CECATTI, 2011). A escolha do melhor método para indução do parto deve considerar os seguintes critérios: efetividade, segurança, custo, facilidade de administração e conforto para a mãe (SOUZA; AMORIM; NETO, 2010).

A indução é, portanto, uma forma de intervenção medicamentosa do parto e por isso deve ser evitada como um procedimento de rotina. Monteschio et al. (2016) realizaram um estudo com 358 puérperas atendidas pelo sistema público de saúde que apontou alta prevalência da medicalização do parto. Aindução foi realizada em $42,2 \%$ dos partos, número inferior ao encontrado na presente pesquisa, e foi mais frequente nas primigestas. Para as autoras, a indução é um procedimento intervencionista do parto que faz parte de uma cascata de procedimentos e associa-se à amniotomia, que se refere ao rompimento artificial da bolsa, e à episiotomia.

Em relação à episiotomia, obteve-se o dado de que $93,8 \%(n=15)$ passaram pelo procedimento, ou seja, das participantes que tiveram parto normal, apenas uma não foi submetida a esta intervenção. Episiotomia é um procedimento cirúrgico no qual o obstetra realiza uma incisão no períneo, para aumentar o canal vaginal durante o parto normal (BORGES; SERRANO; PEREIRA, 2003; PREVIATTI; SOUZA, 2007). É preciso que o profissional médico seja habilitado para suturar lacerações e episiotomias de modo adequado, devendo receber treinamento para isso (BRASIL, 2001). Como todo ato cirúrgico, a episiotomia pode levar a algumas complicações como infecção, dor, edema, hematomas, deiscência (abertura da sutura), abscesso (acúmulo de pus), incontinência de gazes e de fezes etc (PEREIRA; PINTO, 2011). Em 1996 o Ministério da Saúde já recomendava que este procedimento deveria ser realizado em situações específicas, como: sinais de sofrimento fetal, progressão insuficiente do parto e ameaça de laceração de terceiro grau (incluindo laceração de terceiro grau em parto anterior) (BRASIL, 2001).

$O$ dado que reflete a alta incidência deste procedimento na presente pesquisa vai ao encontro do alerta da Organização Mundial da Saúde (OMS, 2011) sobre os índices deste procedimento no Brasil alcançarem $90 \%$ dos partos, a margem recomendada seria de $15 \%$. Em parte, a relação verticalizada entre a equipe de saúde e o desconhecimento da mulher sobre as reais indicações do procedimento favorecem esses números. Pompeu et al. (2017) realizaram uma pesquisa com objetivo de identificar o conhecimento de puérperas sobre a episiotomia, e os resultados revelaram falta de conhecimento das participantes e de esclarecimento da equipe de saúde sobre o termo. O procedimento era realizado, muitas vezes, sem conhecimento e consentimento da mulher e, neste sentido, "os relatos evidenciam que o corpo da mulher é tido como objeto passivo de intervenções e que sua autonomia é desvalorizada" (POMPEU et al., 2017, p. 6). A falta de informação das mulheres, concluíram as autoras, é um fator que contribui para a sua realização como procedimento de rotina, o que, por sua vez, é considerado violência obstétrica.

A literatura aponta a dor do parto normal como uma das motivações para a escolha da via de parto cesárea (CÂMARA et al., 2016; BARBOSA et al., 2003; FIGUEIREDO et al., 2010). Pensando 
nisso, foi solicitado às participantes que identificassem o nível da dor sentida no trabalho de parto em uma escala de 1 a 5, e 68,8\% (n=11) das mulheres apontaram nível 5 e 31,2\% (n=5), o nível 4 de dor. Ou seja, a maioria declarou ter sentido os níveis máximos de dor, na escala sugerida, nenhuma indicou nível menor. Os dados mostram que a intensidade da dor nesta via de parto é uma realidade.

O estudo de Ronconi et al. (2010) investigou 60 puérperas e seus obstetras sobre a percepção de dor do trabalho de parto. Os resultados apontaram dados similares aos da presente pesquisa, pois aproximadamente $70,0 \%$ das entrevistadas relataram a experiência de dor intensa, porém, apenas $31,6 \%$ dos obstetras concordaram com este nível de dor sentida. A experiência da dor moderada foi relatada por $60,0 \%$ dos obstetras e apenas $26,6 \%$ das puérperas. O nível leve de dor foi relatado por $3,33 \%$ das puérperas e por $8,33 \%$ dos obstetras. O contraste nas opiniões das puérperas e dos obstetras releva uma subestimação dos níveis de dor sentidos no trabalho de parto por parte dos profissionais, o que pode fortalecer o sentimento de impotência e vulnerabilidade das parturientes. Ainda, é importante salientar que a resposta a esta sensação é amplamente variável, pois ela pode ser influenciada por aspectos psicológicos e culturais e que essa noção precisa permear as práticas dos profissionais de saúde, tendo em vista a otimização de ações que humanizem o processo.

Um fator que tem sido apontado como relevante no alívio da dor é a presença de doulas. Na presente pesquisa, $81,3 \%(\mathrm{n}=13)$ não tiveram auxílio desta profissional. "Doula" é uma palavra de origem grega que significa mulher que serve, que dá apoio emocional e físico a outras mulheres, durante e após o trabalho de parto (SOUZA; DIAS, 2010). No contexto hospitalar, o papel desta profissional é explicar sobre o progresso do trabalho de parto e procedimentos obstétricos que devem ser realizados, prestar constante apoio à gestante e ao acompanhante, sugerindo medidas para que a parturiente obtenha maior conforto durante o processo do parto, assim como orientação sobre a necessidade do contato físico e apoio emocional (BRASIL, 2001).

Em Santa Catarina a Lei $n^{\circ} 16.869$, de 15 de janeiro de 2016, garante a presença de doulas durante todo o período de trabalho de parto, durante o parto e no pós-parto imediato (SANTA CATARINA, 2016) e isso representa um avanço considerável na direção da humanização da atenção à gestante. Porém, Alves (2018) explica que no Brasil a presença das doulas nas maternidades está em processo de conquista, havendo ainda resistência e desconhecimento de sua função por parte das equipes de saúde. Os dados da presente pesquisa, embora referentes a uma amostra pequena e não generalizável, apontam para um acesso limitado das gestantes aos serviços desta profissional.

O acompanhamento da parturiente pela doula reduz a duração do trabalho de parto, o uso de medicações para alívio da dor e o número de partos operatórios (BRASIL, 2001). Promover uma escuta ativa, deixar a mulher falar quando e o que quiser, comunicar-se através do toque, da atitude e do olhar são ações que promovem a autoconfiança da mulher, fazendo com que ela acredite na sua capacidade de parir (SOUZA; DIAS, 2010). No estudo de Alves (2018), realizado com cinco gestantes de 18 a 36 anos, residentes em São Paulo, os dados mostraram maiores níveis de autoestima e menores indicadores de depressão pós-parto nas gestantes que participaram da intervenção com doula desenvolvida para a pesquisa, em relação às que não participaram. Neste sentido, pode-se pensar na atuação da doula como um recurso fundamental em relação às metas de humanização do parto.

Quanto à analgesia, 68,8\% $(\mathrm{n}=11)$ das mulheres não receberam nenhum tipo. Cumpre ressaltar que se considera uma limitação desta pesquisa o não acesso ao tipo de analgesia a que as mulheres se referiram, ao responder à pergunta. Porém, o número obtido de mulheres que não tiveram nenhum tipo de analgesia ainda é menor do que o encontrado no estudo realizado por Pinheiro e Bittar (2012), com 31 puérperas que passaram por parto normal e 20 profissionais de saúde, no qual nenhuma participante recebeu algum tipo de analgesia. O mesmo estudo apontou que a maioria dos médicos e dos anestesistas consideraram desejável realizar a analgesia em parto normal. Os médicos elencaram o uso do fórceps e o prolongamento do período expulsivo como principais pontos negativos do procedimento neste tipo de parto. As principais vantagens citadas pelos profissionais, incluindo agora enfermeiros, foram o alívio da dor e maior conforto e satisfação da parturiente. 
Segundo as portarias do Ministério da Saúde (2.815 de 1998 e, posteriormente, a 572 de 2000) é direito da mulher obter meios que aliviem a dor durante o trabalho de parto. Durante o pré-natal, a gestante deve ser esclarecida quanto às formas de analgesia disponíveis, suas vantagens, desvantagens e limitações (BRASIL, 2001). Existem três métodos de controle da dor durante o trabalho de parto: não farmacológicos, farmacológicos sistêmicos e farmacológicos regionais. Dentre os não farmacológicos pode-se citar o método psicoprofilático, que consiste na psicoeducação referente à fisiologia do parto e exercícios físicos e respiratórios (BRASIL, 2001). Outro método não farmacológico é colocar o corpo da parturiente em movimento, orientando posições verticais que melhoram a evolução e favorecem o parto vaginal (BIO; BITTAR; ZUGAIB, 2006). O banho, a deambulação, o cavalinho e a bola de parto também são bastante utilizados no processo de parto normal (SESCATO; SOUZA; WALL, 2008).

O método farmacológico sistêmico consiste na aplicação de medicação parenteral, que pode ser via intravenosa, intramuscular e subcutânea. A via intravenosa é a mais eficiente, pois age mais rápido no alívio da dor. Os métodos farmacológicos regionais, que consistem na deposição de anestésicos próximo às vias de condução nervosa, permitem a não depressão do feto e possibilitam maior cooperação da mãe no processo do parto (BRASIL, 2001). A anestesia peridural lombar ou sacral realiza o bloqueio dos ramos do pudendo e do cutâneo posterior da coxa, necessário quando se realizam episiotomias laterais. A anestesia que tem mais vantagem é a peridural lombar contínua, pois promove a ausência de dor, efeito prolongado, controle da intensidade e extensão do bloqueio, ausência de depressão respiratória materna e fetal e versatilidade em situações especiais, como cesárea de urgência e eclampsia (BRASIL, 2001).

$\mathrm{O}$ uso da analgesia em partos normais parece representar um debate em aberto que apresenta polarização de opiniões. Para Pinheiro e Bittar (2012) a analgesia ainda é pouco realizada em muitos hospitais, mesmo sendo um direito assegurado legalmente. As autoras ressaltam que a defesa da aplicação de analgesia em uma perspectiva de humanização não é frequente, por se tratar de mais uma intervenção médica, reduzindo o protagonismo da mulher.

\subsection{ATENÇÃO DA EQUIPE DE SAÚDE}

Para investigar como as mulheres avaliavam da atenção ofertada pela equipe durante o parto normal e cesáreo, foi utilizada uma escala Likert de quatro pontos. Para esta análise foram consideradas as respostas das participantes que tiveram apenas um tipo de parto $(n=25)$. Os resultados são apresentados na Tabela 2:

Tabela 2: Níveis de satisfação quanto à qualidade do atendimento da equipe de saúde no parto

\begin{tabular}{lcccc}
\hline Niveis & Normal & Normal & Cesárea & Cesárea \\
& $(\%)$ & $(f)$ & $(\%)$ & $(f)$ \\
\hline Ótima & $38,5 \%$ & 5 & $72,7 \%$ & 8 \\
Boa & $30,8 \%$ & 4 & $9,1 \%$ & 1 \\
Ruim & $23,1 \%$ & 3 & $18,2 \%$ & 2 \\
Péssima & $7,7 \%$ & 1 & $00,0 \%$ & 0 \\
\hline Total & $100 \%$ & 13 & $100 \%$ & 11 \\
\hline
\end{tabular}

$f:$ número de respostas, não de participantes.

Fonte: Própria pesquisa.

A partir dos Tabela 2 percebe-se que o nível da satisfação ótimo obteve uma pontuação maior $(72,7 \%$, $\mathrm{n}=8$ ) nas respostas das mulheres que tiveram apenas parto cesáreo. No somatório, vê-se que há maiores índices de avaliação positiva entre as mulheres que tiveram apenas parto cesáreo $(81,8 \%)$ do que entre as que 
tiveram apenas o normal $(69,3 \%)$. De modo geral, pode-se pensar que houve maiores níveis de satisfação em relação ao atendimento da equipe de saúde pelas mulheres que tiveram apenas parto cesáreo.

A literatura sugere que a falta de informação adequada influencia o medo da mulher em relação ao parto normal. Ainda existe pouca informação sobre o parto disponível para a mulher, por isso, ele é relacionado à insegurança e a muita dor. Em função disso, a maioria das mulheres nem mesmo reconhece quando a violência obstétrica acontece (BARBOSA; FABBRO; MACHADO, 2017). A relação entre equipe e gestante é de suma importância para o parto, uma vez que a confiança, o acolhimento, o apoio e a comunicação são essenciais para um modelo humanizado de cuidado (OLIVEIRA; PENNA, 2018; PIMENTEL, 2015; BARBOSA; FABBRO; MACHADO, 2017). Alerta-se ainda que, neste cenário, permeado por medo e exposição à violência obstétrica, a cesárea eletiva é cada vez mais usada pelas mulheres para fugir do desconhecido e ter uma proteção contra a dor e a humilhação (MALDONADO, 2013).

Lagomarsino et al. (2013, p. 686) relacionam o medo da mulher do parto normal à institucionalização do parto pela medicina, que limita suas possibilidades de apropriar-se do conhecimento sobre sua fisiologia. Nas palavras das autoras:

A cultura medicalizada de atenção ao parto pode comprometer a possibilidade de a mulher conhecer, apropriar-se e dominar as manifestações do corpo, contribuindo para crenças de que o parto vaginal é perigoso e potencializando sentimentos de insegurança e medo em relação a qualquer decisão em prol desse parto.

Nesse sentido, entende-se que estreitamente ligada ao medo da mulher do parto normal está a terceirização institucional de todo o processo, desde a gestação até o parto em si. Faz-se necessário um resgate pela mulher do entendimento e das decisões concernentes ao seu corpo.

\subsection{RECUPERAÇÃO PÓS-PARTO}

Foram investigados os níveis de satisfação das participantes quanto a sua recuperação pós-parto. Estes resultados estão dispostos na Tabela 3.

Tabela 3: Níveis de satisfação com a recuperação no pós-parto

\begin{tabular}{lcccc}
\hline Níveis & Normal & Normal & Cesárea & Cesárea \\
& $(\%)$ & $(f)$ & $(\%)$ & $(f)$ \\
\hline Ótima & $53,8 \%$ & 7 & $50,0 \%$ & 6 \\
Boa & $15,4 \%$ & 2 & $33,3 \%$ & 4 \\
Ruim & $15,4 \%$ & 2 & $16,7 \%$ & 2 \\
Péssima & $15,4 \%$ & 2 & $00,0 \%$ & 0 \\
\hline Total & $100 \%$ & 13 & $100 \%$ & 12 \\
\hline
\end{tabular}

f: número de respostas, não de participantes.

Fonte: Própria pesquisa.

Pode-se perceber que $83,3 \%$ das participantes que tiveram apenas parto cesáreo consideraram entre boa e ótima a sua recuperação pós-parto. Enquanto que, nas mulheres que experienciaram apenas o parto normal, 69,2\% fizeram esta avaliação. Quanto aos níveis de satisfação negativos, obtiveram-se maiores percentis nas mulheres que tiveram apenas parto normal $(30,8 \%)$. De modo geral, compre- 
ende-se, pelos dados apresentados, que as mulheres que tiveram apenas parto cesáreo se mostraram mais satisfeitas com a recuperação no pós-parto.

De acordo com Kottwitz, Gouveia e Gonçalves (2018), Melo, Davim e Silva (2015) e Ferreira Junior et al. (2017), na maioria das vezes o pós-parto oriundo do parto normal é mais bem avaliado pelas mulheres, pois este tipo de parto proporciona uma recuperação mais rápida. A cesárea tem a característica de não provocar dor na hora do parto, mas demanda uma recuperação lenta. Neste sentido, o resultado obtido no presente estudo vai na contramão do que apresenta a literatura. Um ponto que pode ser relevante na compreensão deste dado é o fato de apenas uma participante não ter passado por episiotomia. Este procedimento causa grande desconforto e pode implicar em dispaurenia, hemorragia, incontinência urinária, dificuldades no autocuidado, e no cuidado com o bebê, por conta da dor oriunda do corte (COSTA et al., 2015).

\subsection{AMAMENTAÇÃO NA PRIMEIRA HORA DE VIDA}

Entre as mulheres que tiveram apenas parto normal, $84,6 \%(\mathrm{n}=11)$ amamentaram logo na primeira hora de vida da criança, entretanto, daquelas que tiveram apenas parto cesáreo, 41,7\% $(n=5)$ amamentaram neste período. Sendo assim, é possível observar que houve mais ocorrências de amamentação na primeira hora de vida da criança em mulheres que tiveram parto normal. Este dado concorda com a literatura, pois, segundo Pereira et al. (2013), o parto normal aumenta a chance de o bebê ter contato com o corpo da mulher nos primeiros minutos de vida e facilita a percepção de sinais da criança que indicam fome, ou seja, de que ela está pronta para mamar. De outro lado, no parto cesáreo é recorrente o início tardio da amamentação. O estudo de Boccolini et al. (2011) apresenta resultados nesta direção, segundo os autores, o parto cesáreo reduziu pela metade a prevalência da mamada na primeira hora de vida do bebê nas maternidades. Os autores sugerem que esta relação parece associar-se com procedimentos pós-cirúrgico a que a mãe precisa se submeter.

$\mathrm{O}$ ato de amamentar é muito importante para nutrir a criança, mas vai além disso, uma vez que engloba uma relação entre mãe e filho e tem reflexos no estado nutricional da criança, na melhora do bebê em desenvolver suas defesas contra infecções, em questões fisiológicas e no desenvolvimento emocional e cognitivo (BRASIL, 2009). Quando realizada na primeira hora de vida, a amamentação tem um efeito protetor sobre a mortalidade neonatal (BOCCOLINI et al., 2013).

\subsection{PRESENÇA DE ACOMPANHANTE}

A Tabela 4 apresenta os resultados sobre as fases em que as participantes tiveram ou não acompanhante, por tipo de parto, considerando somente as participantes que tiveram apenas um tipo de parto.

Tabela 4: Presença de acompanhante no parto

\begin{tabular}{lcc}
\hline Período & Parto Normal & Parto Cesáreo \\
& $(f)$ & $(f)$ \\
\hline Nenhum & 1 & 0 \\
Somente no pré-parto & 2 & 0 \\
Somente no parto & 1 & 1 \\
Somente no pós-parto & 2 & 4 \\
Somente no pré-parto e no pós-parto & 1 & 0 \\
No pré-parto, no parto e no pós-parto & 6 & 7 \\
\hline
\end{tabular}

$f:$ número de respostas, não de participantes.

Fonte: Própria pesquisa. 
De acordo com a Tabela 4, no parto cesáreo as participantes tiveram maior presença de acompanhante nas três fases, pré-parto, no parto e no pós-parto $(n=7)$. Chama a atenção que, entre as mulheres com apenas o parto cesáreo, cinco tiveram presença do acompanhante apenas no período pós-parto. Em relação às com apenas o parto normal, cinco delas tiveram acompanhante em apenas um dos três períodos e uma não teve em nenhum período.

Vendrúscolo e Kruel (2017) investigaram 86 puérperas internadas em uma maternidade pública sobre a frequência de acompanhantes e as razões para a não presença deles. Os resultados apontaram que $42,0 \%$ das mulheres estiveram acompanhadas por alguém de sua escolha, sendo o pai da criança o acompanhante mais frequente. No estudo, foi observado o desejo de ter acompanhante durante o parto na maior parte das mulheres, porém isto não ocorreu com mais da metade da amostra. Dentre as razões mais citadas para a não presença do acompanhante sobressaíram-se questões relacionadas à disponibilidade pessoal da parturiente, à organização da família e à recusa da equipe de saúde. Na presente pesquisa as razões para a ausência do acompanhante em todas as fases da parturição não foram investigadas.

A comparação com outros estudos também fica prejudicada em função de este ter investigado a presença do acompanhante nas três fases que envolvem o parto, e não apenas no parto em si. Porém, é relevante apontar a importância da presença de um acompanhante durante todo o processo do parto, com ênfase na fase de trabalho de parto (pré-parto) em casos de parto normal, pelos benefícios que esta pessoa proporciona à gestante. Estudo realizado por Teles et al . (2010), com 105 puérperas internadas em alojamento conjunto de maternidade escola no Estado do Ceará, apontou que o fator que mais influenciou na percepção positiva ou negativa sobre a experiência do parto foi a presença de um acompanhante (46,6\%). O acompanhante provia, principalmente, apoio emocional. Dodou et al. (2014) investigaram 20 puérperas sobre sua percepção acerca das contribuições do acompanhante durante parto. Os resultados mostraram que a presença do acompanhante traz conforto para a dor e a solidão, aumentando os níveis de confiança e de segurança da mulher neste processo. As autoras concluem que a presença do acompanhante, por promover força e apoio, contribui para a humanização do parto.

No Brasil, a Lei $n^{\circ}$. 11.108/2005 garante a presença de um acompanhante, à escolha da mulher, nos períodos de pré-parto, parto e pós-parto imediato (BRASIL, 2005). Porém, mesmo estando a lei em plena vigência, este direito da mulher permanece desconhecido pela maior parte dos acompanhantes. Esse fator denuncia a escassa divulgação deste direito pelos dispositivos de saúde (FRUTUOSO; BRÜGGEMANN, 2013). As autoras recomendam que os esclarecimentos e a orientação para a escolha do acompanhante sejam feitos já no pré-natal, tanto em relação aos seus direitos, quanto sobre as funções do acompanhante no processo de parto. Adicionalmente, a importância do acompanhante em todo o processo e o esclarecimento de mitos relacionados à sua presença devem ser feitos com a equipe de saúde, como apontam os resultados da pesquisa de Brüggemann et al. (2015, p. 152), que revelou que "o impedimento do acompanhante está pautado em ideias preconcebidas de que ele pode interferir negativamente na organização do processo de trabalho", indo na contramão das propostas atuais no Ministério da Saúde (BRASIL, 2005).

\subsection{INFLUÊNCIAS NA ESCOLHA DA VIA DE PARTO}

A Tabela 5 apresenta as respostas à questão que solicitava às participantes assinalarem os fatores que influenciaram na sua escolha da via de parto. Era possível selecionar mais de uma alternativa.

Os dados da Tabela 5 mostram que o fator mais influente na escolha da via de parto foi a opinião do(a) obstetra/médico(a) (n=20). De outro lado, chamou a atenção o dado que mostra a opinião do(a) enfermeiro(a) $(n=2)$ como o fator de menor influência nesta escolha.

A autoridade médica é considerada de relevância na escolha sobre a via de parto entre as mulheres, mesmo em mulheres com maior escolaridade e renda, sobre as quais há expectativas de maior autonomia nas decisões relacionadas ao seu corpo. Esse dado também foi verificado no estudo de Oliveira e Penna 
(2018), em que as participantes relataram a influência dos profissionais da saúde na escolha da via de parto. Já, no estudo de Kottwitz, Gouveia e Gonçalves (2018), a maioria das participantes afirmou que nem sequer foram questionadas sobre sua preferência pelo tipo de parto. O médico traz consigo a representação de maior segurança e menor sofrimento com o parto cesáreo (PIRES et al. 2010),

Tabela 5: Fatores que influenciaram na escolha da via de parto

\begin{tabular}{lc}
\hline Fatores & $f$ \\
\hline Opinião do(a) obstetra/médico(a) & 20 \\
Opinião de familiares & 12 \\
Outros & 9 \\
Artigos científicos e outros textos de pesquisa & 8 \\
Sites, blogs, páginas do Facebook, canais do Youtube, etc. & 5 \\
Opinião de amigos(as) & 3 \\
Opinião do(a) enfermeiro(a) & 2 \\
\hline Total & 59 \\
\hline
\end{tabular}

f: número de respostas, não de participantes.

Fonte: Própria pesquisa.

A opinião de familiares apareceu em segundo lugar $(n=12)$ como fator de influência da decisão da mulher. Pesquisas mostram que a influência familiar tem grande relevância para as mulheres na hora da escolha da via de parto (SILVA; PRATES; CAMPELO, 2014; MEDEIROS et al., 2017). Nesta direção, Lagomarsino et al. (2013, p. 686) complementam:

As mulheres inseridas em sua cultura, no interior da qual está sua família, são cercadas de vivências, experiências, valores e crenças que dão forma às histórias que modelam preferências e as escolhas no nascimento de um filho. Em meio às pessoas da família, destacase a influência materna na preferência e na decisão por determinada via de parto.

A opção "outros" ficou em terceiro lugar. Nesta categoria entraram, porém, respostas pouco específicas em relação à influência na escolha, ou que não definiram quais outros fatores seriam estes. Esta categoria foi seguida de perto pela que fez referência a materiais científicos, posição de certa forma esperada, em função das características da amostra, que se compõe de acadêmicas.

Os profissionais da Enfermagem, pouco citados como fator de influência na escolha da vida de parto na presente pesquisa, em sua prática tendem a dar um importante apoio para as mulheres por meio de cursos que envolvam aspectos relacionados à gestação, oferecendo também medidas de conforto, como permitir acompanhante, banho, um ambiente calmo, também evitam procedimentos como o enema, tricotomia e uso de ocitocina (CASTRO; CLAPIS, 2005).

A multiplicidade de fatores que influencia a escolha da via de parto pela mulher demanda que, já durante o pré-natal, as práticas de orientação à gestante sejam implementadas. Estas estratégias possibilitam o exercício de sua autonomia, pois, neste processo, a mulher tem a oportunidade de amadurecer sua escolha, com base em informações bem fundamentadas. Contudo, essas atitudes precisam ser constantes até o nascimento da criança, pois podem ocorrer mudanças no processo de gestação, proporcionando uma alteração na escolha prévia da mulher (PEREIRA; BENTO, 2011).

Uma leitura global dos dados obtidos na presente pesquisa parece apontar para um relacionamento mais positivo das mulheres com o parto cesáreo, do que com o parto normal, considerando as variáveis 
satisfação com o tipo de parto, com a atenção da equipe de saúde e até mesmo com a recuperação pós-parto. Ressalta-se que esta última variável tende a ser um fator positivo influente na escolha das mulheres pelo parto normal, que geralmente se associa a uma recuperação mais rápida e facilitada. A exceção está na amamentação do recém-nascido na primeira hora de vida, com melhores níveis entre as mulheres que tiveram parto normal. É possível levantar a hipótese de que os resultados obtidos em variáveis que se relacionavam apenas a partos normais (altos níveis de episiotomia, indução, de dor experienciada e baixos níveis de presença de doula e de analgesia) contribuíram para os piores resultados encontrados no relato das experiências das mulheres com o parto normal, em contraposição ao cesáreo. Tais hipóteses podem ser testadas em estudos futuros.

\section{CONSIDERAÇÕES FINAIS}

Foi objetivo desta pesquisa investigar as características gerais das experiências de parto e pós-parto de acadêmicas de Psicologia. A maioria das mulheres considerou que sua opção pelo tipo de via de parto escolhido foi respeitada e os dados demonstraram números semelhantes de partos normais e cesáreos, indicando, porém, níveis maiores de parto cesáreo do que os sugeridos como adequados pelos principais órgãos da saúde, mundial e nacionalmente.

Quando observados dados apenas referentes à experiência das participantes com o parto normal, sobressaiu-se a informação de que uma proporção expressiva passou por indução e, principalmente, episiotomia. Estes são procedimentos que devem ser utilizados em casos específicos e não como rotina nos trabalhos de parto. Neste sentido, sugere-se a hipótese de que os menores níveis de satisfação com o tipo de parto, com o atendimento da equipe de saúde e com a recuperação pós-parto obtidos nos relatos das mulheres que tiveram parto normal relacionam-se com a vivência com estes procedimentos. Adicionalmente, o pouco acesso à doula, associado aos altos níveis de dor no trabalho de parto relatados pelas participantes podem ser contribuintes para uma avaliação mais negativa do parto normal. De outro lado, maiores frequências de amamentação na primeira hora de vida do bebê foram observadas em mães que tiveram parto normal, informação que vai ao encontro do que mostra a literatura científica.

Em relação ao conhecimento sobre aspectos ligados às vias de parto, a maioria das participantes se disse bem informada sobre o tema e classificou seu nível de conhecimento como bom. Porém, porcentagens consideráveis, embora menores, concordaram pouco ou discordaram que o parto normal seja mais benéfico para a mãe e para a bebê e que o parto seja um evento fisiológico, não médico. Essa constatação aponta para uma demanda de orientação, pautada em evidências e desprovida de um viés medicamentoso e biomédico.

No tocante aos fatores que influenciaram a escolha sobre a via de parto das mulheres, obteve-se o dado de que a opinião médica foi preponderante, em detrimento da opinião da equipe de Enfermagem, que consistiu na categoria menos mencionada. $\mathrm{O}$ desconhecimento das funções e da relevância da atuação do enfermeiro em todas as fases do parto e, de maneira diferenciada, no pré-natal, é um dado preocupante a ser investigado de maneira mais ampliada por outras pesquisas. A família também apareceu como fator relevante neste processo decisório, seguida da leitura de materiais científicos sobre a temática. Esta opção se explica pela característica acadêmica da amostra.

Os resultados, de forma geral, apontam para a sugestão de que a escolha da via de parto da mulher tem como condicionantes importantes a qualidade das práticas da equipe de saúde, em todos os períodos relacionados ao parto. Quando as mulheres são expostas a situações de violência obstétrica, o que inclui a realização da episiotomia e da indução de parto como procedimentos rotineiros, sua experiência é passada a outras mulheres. Gera-se, assim, como expôs Maldonado (2013), uma cultura da cesariana, que perpassa questões de cuidado, intervenção e das influências sociais da gestante.

Entende-se que a amostra por conveniência, constituída apenas por mulheres estudantes de Psicologia, o número reduzido de participantes, a ausência de controle de influência de fatores como 
idade e condições socioeconômicas e a falta de conhecimento aprofundado sobre questões importantes sobre algumas variáveis, como razão para não ter acompanhante em alguns períodos ou se os casos de episiotomia foram informados e consentidos anteriormente a sua realização, representam limitações para este estudo. Em função disto, os dados precisam ser interpretados com cautela, por serem pouco representativos em relação a outras populações. Entretanto, o estudo trouxe informações importantes acerca da experiência do parto, o levantamento de tais informações pode contribuir para a elaboração e fortalecimento de estratégias efetivas de empoderamento e humanização para gestantes na tomada de decisão sobre seu parto. 


\section{Referências}

ALVES, D. E. Bem-estar da gestante: avaliação de um modelo de pesquisa e intervenção da doula. 2018. 46f. Dissertação (Mestrado em Psicologia da Saúde). Escola de Ciências Médicas e da Saúde da Universidade Metodista de São Paulo, São Bernardo do Campo, 2018.

ANDRADE, B. P.; AGGIO, C. DE M. Violência obstétrica: a dor que cala. Anais do III Simpósio Gênero e Políticas Públicas. Universidade Estadual de Londrina, 27 a 29 de maio de 2014.

BARbosa, G. P. et al. Parto cesáreo: quem o deseja, em quais circunstâncias. Cadernos de Saúde Pública, v.19, n.9, p.1611-1620, 2003.

BARBOSA, J. F.; TOÉ, T. F. D.; SIMÕES, P. W. Incidência de cesariana entre usuárias de um plano de saúde privado. Medicina, v.48, n.4, p.336-341, 2015.

BARBOSA, L. C.; FABBRO, M. R. C.; MACHADO, G. P. R. Violência obstétrica: revisão integrativa de pesquisas qualitativas. Avances em Enfermagem, v.35, n.2, p.190-207, 2017.

BARROS, T. C. X. de. et al. Assistência à mulher para a humanização do parto e nascimento. Revista de Enfermagem UFPE On-Line, v.12, n.2, p.554-558, 2018.

BIO, E. B.; BITTAR, R. E.; ZUGAIB, M. Influência da mobilidade materna na duração da fase ativa do trabalho de parto. Revista Brasileira de Ginecologia \& Obstetrícia, v.28, n.11, p.671-679, 2006.

BRASIL. Ministério da Saúde. Parto, aborto e puerpério: assistência humanizada à mulher. Brasília, 2001.

BRASIL. Lei n 11.108, de 7 de abril de 2005. Altera a Lei n 8.080 , de 19 de setembro de 1990 , para garantir às parturientes o direito à presença de acompanhante durante o trabalho de parto, parto e pós-parto imediato, no âmbito do Sistema Único de Saúde - SUS. Diário Oficial da União. Brasília, 2005.

BRASIL. Ministério da Saúde. Pesquisa Nacional de Demografia e Saúde da Criança e da Mulher - PNDS 2006: dimensões do processo reprodutivo e da saúde da criança. Brasília, 2009.

BRASIL. Ministério da Saúde. Cadernos Humaniza SUS. Humanização do parto e do nascimento. v. 4. Brasília, 2014. BRASIL. Ministério da Saúde. Portaria n ${ }^{\circ} 306$ de 28 de março de 2016. Aprova as Diretrizes de Atenção à Gestante: a operação cesariana. Brasília, 2016.

BOCCOLINI, C. S. et al. Fatores associados à amamentação na primeira hora de vida. Revista Saúde Pública, v.45, p.69-78, 2011.

BOCCOLINI, C. S. et al. A amamentação na primeira hora de vida e mortalidade neonatal. Jornal de Pediatria, v.89, n.2, p.131-136, 2013.

BORGES, B. B.; SERRANO, F.; PEREIRA, F. Episiotomia: uso generalizado versus selectivo. Revista Acta Médica Portuguesa, v.16, p.447-454, 2003.

BRÜGGEMANN, O. M. et al. No parto vaginal e na cesariana: acompanhante não entra: discursos de enfermeiras e diretores técnicos. Revista Gaúcha de Enfermagem, v. 36, n.esp., p. 152-158, 2015.

CÂMARA, R. et al. Cesariana a pedido materno. Revista do Colégio Brasileiro de Cirurgiões, v.43, n.4, p.301-310, 2016.

CASTRO, J. C.; CLAPIS, M. J. Parto humanizado na percepção das enfermeiras obstétricas envolvidas com a assistência ao parto. Revista Latino-Americana de Enfermagem, v.13, n.6, p.960-967, 2005.

CONSELHO FEDERAL DE MEDICINA. Resolução CFM n 2.144/2016 Brasília, 2016. Disponível em: http://www. portalmedico.org.br/resolucoes/CFM/2016/2144_2016.pdf Acesso em: 03/03/2018.

COSTA, L. M. et al. Episiotomia no parto normal: incidência e complicações. Revista Cultural e Científica da UNIFA- 
CEX, v.13, n.1, p.173-187, 2015.

DIAS, M. A. B. et al. Trajetória das mulheres na definição pelo parto cesáreo: estudo de caso em duas unidades do sistema de saúde suplementar do estado do Rio de Janeiro. Ciência \& Saúde Coletiva, v.13, n.5, p.1521-1534, 2008.

DODOU, H. D. et al. A contribuição do acompanhante para a humanização do parto e nascimento: percepções de puérperas. Escola Anna Nery, v.18, n.2, p.262-269, 2014.

DOMINGUES, R. M. S. M. et al. Processo de decisão pelo tipo de parto no Brasil: da preferência inicial das mulheres à via de parto final. Caderno de Saúde Pública, v.30, n.1, p.101-116, 2014.

DOMINGUES, R. M. S. M.; SANTOS, E. M. dos; LEAL, M. do C. Aspectos da satisfação das mulheres com a assistência ao parto: contribuição para um debate. Cadernos de Saúde Pública, v.20, n. 1, p.52-62, 2004.

EUFRÁSIO, L. S. Prevalência e fatores associados ao parto cesárea no contexto regional brasileiro em mulheres em idade reprodutiva. 2017. 90f. Tese (Doutorado em Fisioterapia). Programa de Pós-Graduação em Fisioterapia. Centro de Ciências da Saúde. Universidade Federal do Rio Grande do Norte, Rio Grande do Norte. 2017.

FERREIRA JUNIOR, A. R. et al. Discurso de mulheres na experiência do parto cesáreo e normal. Revista Saú de.com, V.13, n.2, p.855-862, 2017.

FIGUEIREDO, N. S. V. et al. Fatores culturais determinantes da escolha da via de parto por gestantes. Revista Hospital Universitário de Juiz de Fora, v.36, n.4, p.296-306, 2010.

FRUTUOSO, L. D.; BRÜGGEMANN, O. M. Conhecimento sobre a Lei 11.108/2005 e a experiência dos acompanhantes junto à mulher no centro obstétrico. Texto e Contexto: Enfermagem, v.22, n.4, p.909-917, 2013.

FONSECA, L. M. M.; SCOCHI, C. G. S. Cuidados com o bebê prematuro: orientações para a família. Ribeirão Preto: FIERP, 2009.

HADDAD, S. E. M.; CECATTI, J. G. Estratégias dirigidas aos profissionais para a redução das cesáreas desnecessárias no Brasil. Revista Brasileira de Ginecologia e Obstetrícia, v.33, n.5, p.252-262, 2011.

KOTTWITZ, F.; GOUVEIA, H. G.; GONÇALVES, A. de C. Via de parto preferida por puérperas e suas motivações. Escola Anna Nery Revista de Enfermagem, v.22, n.1, p.1-8, 2018.

LAGOMARSINO, B. S. et al. A cultura mediando preferências pelo tipo de parto: entrelaçamento de fios pessoais, familiares e sociais. Revista Mineira de Enfermagem, v.17, n.3, p.688-694, 2013.

LEMES, C. M. et al. Percepção das Puérperas em relação à indução do parto. Revista da Faculdade de Ciências Médicas de Sorocaba, v. 17, n.2, p.86-91, 2015.

MALDONADO, M. T. Psicologia da gravidez. 1. ed. digital. Rio de Janeiro: Jaguatirica Digital, 2013.

MARTINS, M. F. S. V. O programa de assistência pré-natal nos Cuidados de Saúde Primários em Portugal: uma reflexão. Revista Brasileira de Enfermagem, v.67, n.6, p. 1108-1012, 2014.

MEDEIROS, R. M. K. et al. Aspectos relacionados à preferência da gestante pela via de parto. Revista Eletrônica Gestão \& Saúde, v.8, n.1, p.603-621, 2017.

MELO, J. K. F.; DAVIM, R. M. B.; SILVA, R. R. A. S. Vantagens e desvantagens do parto normal e cesariano: opinião de puérperas. Revista de Pesquisa Cuidado é Fundamental, v.7, n.4, p.3197-3205, 2015.

MELO, G. F. Análise da autonomia da gestante na escolha do tipo de parto. 2016. 119f. Dissertação (Mestrado em Ensino na Saúde) - Universidade Federal de Goiás, Goiás, 2016.

MONTESCHIO, L. V. C. et al. Prevalência da medicalização do trabalho de parto e parto na rede pública de saúde. Revista Ciência, Cuidado \& Saúde, v. 15, n. 4, p. 591-598, 2016. 
NASCIMENTO, F. C. V. do; SILVA, M. P. da; VIANA, M. R. P. Assistência de Enfermagem no parto humanizado. Revista de Prevenção de Infeç̧ão e Saúde (REPIS), v. 4, p.1-10, 2018.

OLIVEIRA, V. J.; PENNA, C. M. de M. Cada parto é uma história: processo de escolha da via de parto. Revista Brasileira de Enfermagem, v.71, n.3, p.1304-1312, 2018.

OMS. Organização Mundial da Saúde. Educação para uma maternidade segura: sepsis puerperal: módulos de educação em obstetrícia. 2. ed., 2011.

OMS. Organização Mundial de Saúde. Declaração da OMS sobre taxas de cesáreas. Genebra: WHO, 2014. Disponível em: http://apps.who.int/iris/bitstream/10665/161442/3/WHO_RHR_15.02_por.pdf Acesso em: 27/02/2018.

OMS. Organização Mundial de Saúde. Recommendations on antenatal care for a positive pregnancy experience. 1. Genebra: WHO, 2016. Disponível em: http://www.who.int/reproductivehealth/publications/maternal_perinatal_health/ anc-positive-pregnancy-experience/en/ Acesso em: 21/04/2018.

PATAH, L. E. M.; MALIK, A. M. Modelos de assistência ao parto e taxa de cesárea em diferentes países. Revista de Saúde Pública, v.45, n. 1, p.185-94, 2011

PEREIRA, A. L. F.; BENTO, A. D. Autonomia no parto normal na perspectiva das mulheres atendidas na casa de parto. Revista RENE, v.12, n.3, p.471-477, 2011.

PEREIRA, C. R. V. R. et al. Avaliação de fatores que interferem na amamentação na primeira hora de vida. Revista Brasileira de Epidemiologia, v. 16, n.2, p.525-534, 2013.

PEREIRA, G. V.; PINTO, F. A. Episiotomia: uma revisão de literatura. Ensaios e Ciência: Ciências Biológicas, Agrárias e da Saúde, v.15, n.3, p.183-196, 2011.

PEREIRA, S. B. et al. Boas práticas de atenção ao parto e ao nascimento na perspectiva de profissionais de saúde. Revista Brasileira de Enfermagem, v.71, n.3, p.1393-1399, 2018

PIMENTEL, T. A. Fatores que influenciam na escolha da via de parto cirúrgica: uma revisão Bibliográfica. 2015.23 f. Monografia (Graduação em Enfermagem). Faculdade de Ciências da Educação e Saúde - FACES. Brasília, 2015.

PINHEIRO, B. C.; BITTAR, C. M. L. Percepções, expectativas e conhecimentos sobre o parto normal: relatos de experiência de parturientes e dos profissionais de saúde. Aletheia, v. 37, p. 212-227, 2012.

PIRES et al. A influência da assistência profissional em saúde na escolha do tipo de parto: um olhar sócio antropológico na saúde suplementar brasileira. Revista Brasileira de Saúde Materno Infantil, v.10, n.2, p. 191-197, 2010.

POMPEU, L. C. et al. Prática da episiotomia no parto: desafios para a Enfermagem. Revista de Enfermagem do Centro-Oeste Mineiro, v.7, p. 1-8, 2017.

PREVIATTI, J. F.; SOUZA, K. V. Episiotomia: em foco a visão das mulheres. Revista Brasileira de Enfermagem, v.60, n. 2, p.197-201, 2007.

RISCADO, L. C.; JANNOTTI C. B.; BARBOSA, R. H. S. A decisão pela via de parto no Brasil: temas e tendências na produção de saúde pública. Texto e Contexto Enfermagem, v.25, n.1, p.1-10. 2016.

RONCONI, A. P. L. et al. A dor e a satisfação durante o trabalho de parto em primigestas: visão da parturiente e do obstetra. Revista Dor, v.11, n.11, p-227-281, 2010.

SANTA CATARINA. Lei $\mathrm{n}^{\circ} 16.869$ de 15 janeiro de 2016. Presença de Doulas durante todo o período de trabalho de parto, parto e pós-parto imediato. Diário Oficial de Santa Catarina. Florianópolis, 2016.

SANTOS, R. A. A. dos; MELO, M. C. P. de; LEAL, R. J. M. Experiência do tipo de parto: relato de puérperas através da análise de discurso. Revista Ciências Médicas e Biológicas, v.14, n.1, p.74-81, 2015. 
SESCATO, A. C.; SOUZA, S. R. R. K.; WALL, M. L. Os cuidados não farmacológicos para alívio da dor no trabalho de parto: orientações da equipe de enfermagem. Revista

Cogitare Enfermagem, v.13, n.4, p.585-590, 2008.

SOUZA, K. R. F.; DIAS, M. D. História oral: a experiência das doulas no cuidado à mulher. Revista Acta Paulista de Enfermagem, v.23, n.4, p.493-499, 2010.

SOUZA, A. S. R.; AMORIM, M. M. R.; NETO, C. N. Métodos farmacológicos de indução do trabalho de parto: qual o melhor. Revista Brasileira de Ginecologia e Obstetrícia, v.38, n.5, p.278-287, 2010.

SILVA, S. P. C.; PRATES, R. C. G.; CAMPELO, B. Q. A. Parto normal ou cesariana? Fatores que influenciam na escolha da gestante. Revista de Enfermagem (UFSM), v. 4 n. 1, p. 1-9, 2014.

TELES, L. M. R. et al. Parto com acompanhante e sem acompanhante: a opinião das puérperas. Revista Cogitare Enfermagem, v. 15 , n.4, p. 688-694, 2010 .

UNICEF. Fundo das Nações Unidas para a infância. Quem espera sempre alcança. Brasil, 2017.

VELHO, M. B.; SANTOS, E. K. A.; COLLACO, V. S. Parto normal e cesárea: representações sociais de mulheres que os vivenciaram. Revista Brasileira de Enfermagem, v.67, n.2, p.282-289, 2014

VENDRÚSCOLO, C. T.; KRUEL, C. S. Livre escolha da parturiente pela acompanhante e seus entraves: desafios para a humanização da assistência ao parto. Revista Barbarói, n. 49, p. 52-70, 2017.

WEIDLE, W. G. et al. Escolha da via de parto pela mulher: autonomia ou indução? Caderno Saúde Coletiva, v.22, n.1, p. 46-53, 2014.

$\begin{array}{cl}\text { Histórico } & \text { Recebido em: } 19 / 05 / 2018 \\ & \text { Revisado em: } 19 / 10 / 2018 \\ & \text { Aceito em: } 25 / 10 / 2018 \\ & \text { Concepção: RFG; CDB } \\ & \text { Coleta de dados: CFZ; UGR; PCB; RRG } \\ & \text { Análise de dados: RFG; CDB; CFZ; UGR; PCB; RRG } \\ & \text { Elaboração do manuscrito: RFG; CDB; CFZ; UGR; PCB; RRG } \\ & \text { Crítica - revisões de conteúdo intelectual importante: RFG; CDB } \\ & \text { Aprovação final do manuscrito: RFG; CDB } \\ & \\ & \\ \text { Financiamento } & \text { Não houve financiamento }\end{array}$

